\title{
MAPEAMENTO GEOGRÁFICO DE ATLETAS PARALÍMPICOS BRASILEIROS
}

\author{
GEOGRAPHIC MAPPING OF BRAZILIAN PARALYMPIC ATHLETES
}

\author{
MAPEO GEOGRÁFICO DE ATLETAS PARALÍMPICOS BRASILEÑOS
}

\author{
Andressa Silva*, Fernanda Narciso*, Eduardo Stieler*, Lucas Alves Facundo*, \\ Aline Ângela da Silva Cruz ${ }^{*}$, Alberto Martins Costa**, Patrícia Silvestre*, \\ Marco Túlio de Mello*
}

\begin{abstract}
Palavras chave: Mapeamento geográfico. Esportes para pessoas com deficiência Natação. Atletismo.

Resumo: 0 estudo teve como objetivo mapear geograficamente os atletas paralímpicos brasileiros de natação e atletismo, bem como identificar suas deficiências. Os dados dos atletas foram obtidos junto ao Comitê Paralímpico Brasileiro (CPB), onde buscamos informações sobre os atletas que participaram do Circuito Loterias Caixa de 2015. A amostra foi de 1.708 atletas paralímpicos das modalidades natação e atletismo, sendo 913 da natação e 795 do atletismo. Observou-se que a maioria dos atletas é da região Sudeste $(66 \%)$, seguida das regiões Sul $(11 \%)$, Nordeste $(11 \%)$, Centro-Oeste $(9 \%)$ e Norte $(3 \%)$. Houve predominância de atletas com deficiência físico-motora $(65,5 \%)$, seguida das deficiências visual $(25,1 \%)$ e intelectual $(9,4 \%)$. Concluímos que a região brasileira com maior número de atletas no atletismo e na natação é a Sudeste e a região com menor número foi a Norte. Além disso, encontramos predominância da deficiência físico-motora, tanto no atletismo quanto na natação.
\end{abstract}

Keywords: Geographic Mapping. Sports for Persons with Disabilities. Swimming,. Athletics.

Palabras clave: Mapeo Geográfico. Deportes para Personas con Discapacidad. Natación. Atletismo

Abstract: The study conducted a geographic mapping of Brazilian Paralympic athletes practicing swimming and athletics and identified their disabilities. Data about the athletes were provided by the Brazilian Paralympic Committee (CPB), where we sought information about those who participated in the 2015 competition Circuito Loterias Caixa. The sample consisted of 1,708 paralympic swimming and athletics athletes -913 and 795 respectively. The study found that most athletes came from Brazil's Southeast region (66\%), followed by the South $(11 \%)$, Northeast $(11 \%)$, Center-West $(9 \%)$ and North $(3 \%)$. Athletes with physical-motor disabilities $(65.5 \%)$ were the majority, followed by the visually $(25.1 \%)$ and intellectually (9.4\%) impaired. We concluded that the Brazilian region with the most athletics and swimming athletes is the Southeast while the North region had lowest number. In addition, we found predominance of physical-motor disabilities in both sports.

Resumen: El estudio tuvo como objetivo mapear geográficamente a los atletas paralímpicos brasileños de natación y atletismo, además de identificar sus deficiencias. Los datos de los atletas fueron obtenidos junto al Comité Paralímpico Brasileño (CPB), donde buscamos informaciones sobre los atletas que participaron del Circuito Loterías Caixa de 2015. La muestra fue de 1.708 atletas paralímpicos de la modalidades natación y atletismo, siendo 913 de natación y 795 de atletismo. Se observó que la mayoría de los atletas son de la región Sudeste (66\%), seguida de la Sur (11\%), Nordeste (11\%), CentroOeste (9\%) y Norte (3\%). Se observó un predominio de atletas con deficiencia físico-motora $(65,5 \%)$, seguida de las deficiencias visual $(25,1 \%)$ e intelectual $(9,4 \%)$. Concluimos que la región brasileña con mayor número de atletas en atletismo y natación es la Sudeste y la región con menor número fue la Norte. Además, encontramos predominancia de la deficiencia físico-motora, tanto en el atletismo como en la natación.
*Universidade Federal de Minas Gerais. Belo Horizonte, MG, Brasil. E-mail: silvadressa@gmail.com; fernandanarciso@ hotmail.com; eduardostieler@hotmail.com; lucasafac1996@gmail.com; ninadisiobh@hotmail.com; tmello@demello.net.br

${ }^{* *}$ Comitê Paralímpico Brasileiro. Belo Horizonte, MG, Brasil. E-mail: amcosta@cpb.org.br; patricia@cpb.org.br

Recebido em: 06-12-2018 Aprovado em: 30-05-2019 Publicado em: 06-09-2019

DOI: https://doi.org/10.22456/1982-8918.88691 (c) (1) () Licence 


\section{INTRODUÇÃO}

O esporte adaptado surgiu para atender as necessidades das pessoas com deficiência, favorecendo a inclusão social, além de contribuir para a sua inserção no mundo esportivo. Em 1944, o neurocirurgião Ludwig Guttmann utilizou o esporte como parte do processo de reabilitação dos pacientes na Unidade de Lesões Medulares de Stoke Mandeville, na Inglaterra (PARSONS, WINCKLER, 2012). Na ocasião, o esporte era utilizado para melhorar a qualidade de vida e a condição psicológica dessas pessoas, sendo um elemento motivador para a integração entre os pacientes no ambiente hospitalar (BAILEY, 2008).

A primeira competição oficial para atletas em cadeira de rodas e amputados aconteceu em julho de 1948, no Hospital de Stoke Mandeville, no Reino Unido, uma competição entre os pacientes do Hospital. Em 1952, os Países Baixos se juntaram ao evento, criando a primeira competição internacional de esportes para portadores de deficiência. Em 1960, a nova edição dos Jogos de Stoke Mandeville foi realizada em Roma, Itália, na sequência dos Jogos Olímpicos. Esses foram considerados os primeiros Jogos Paralímpicos da história (STEADWARD, PETERSON, 1997). Os Jogos Paralímpicos incluem atletas com deficiência física (DF), deficiência visual (DV) e deficiência intelectual (DI) que precisam ser avaliados por classificadores, e cada qual receber sua classificação esportiva para poderem competir em uma das 23 modalidades de verão ou nas cinco modalidades de inverno.

O Brasil é um dos países que vêm apresentando grande evolução nas últimas edições dos Jogos Paralímpicos sendo que, desde Sidney (2000) até Rio (2016), apresentou as seguintes

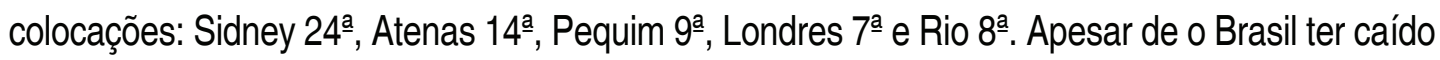
uma colocação na classificação geral dos Jogos Paralímpicos RIO 2016, o número de medalhas da delegação aumentou de 42 para 72 medalhas. Cabe destacar que os Jogos Paralímpicos que ocorreram no Brasil em 2016 foram considerados a maior edição dos Jogos, com 4.333 atletas e 159 países participantes. O Brasil participou com 285 atletas distribuídos em 22 modalidades: Atletismo, Basquete em cadeira de rodas, Bocha, Canoagem, Ciclismo, Esgrima de cadeira de rodas, Futebol de 5, Futebol de 7, Goalball, Halterofilismo, Hipismo, Judô, Natação, Remo, Rugby em cadeira de rodas, Tênis de mesa, Tênis em cadeira de rodas, Tiro com arco, Tiro esportivo, Triatlo, Vela e Voleibol Sentado. As modalidades atletismo e natação foram as que conquistaram o maior número de medalhas durante os Jogos Paralímpicos de Londres 2012 e Rio 2016 (IPC, 2014; CARDOSO, 2018).

O modelo de organização do Comitê Paralímpico Brasileiro (CPB) tem sido exemplo para outros países. Dentre as atividades desenvolvidas, o CPB faz busca ativa de novos talentos para o esporte paralímpico, e, para isto, organiza anualmente as Paralimpíadas Escolares, na cidade de São Paulo, destinada a jovens em idade escolar que apresentam algum tipo de deficiência. Nos últimos anos cerca de 1.000 estudantes, com idade entre 12 e 18 anos, participaram dessa competição. A partir dessa competição, os atletas que apresentam algum potencial e talento para praticar o esporte paralímpico são acompanhados pelo CPB, sendo convocados para fazerem parte das seleções de jovens e assim se qualificarem para participar de eventos nacionais e internacionais e posteriormente comporem as seleções permanentes do CPB. O principal evento nacional para o esporte paralímpico brasileiro é o Circuito Loterias Caixa, que a partir de 2011 passou a ser uma competição de alto rendimento a nível nacional (FURTADO, 2017). Desta maneira, o CPB investe na detecção de novos talentos dando o suporte necessário e realizando 
o seu monitoramento. Esses atletas começam a participar de treinamentos específicos e receber um atendimento de uma equipe qualificada de profissionais que trabalham com 0 alto rendimento no Centro de Treinamento Paralímpico em São Paulo, para que se qualifiquem e se destaquem nas competições, para que no futuro possam compor a seleção permanente de atletas que representam o país nos Jogos Paralímpicos, que ocorrem a cada quatro anos.

Considerando que são escassos os estudos que apresentam dados quantitativos sobre pessoas com deficiência que praticam o esporte paralímpico (DUARTE; SILVA, 2012), mais estudos são necessários no Brasil para conhecer melhor essa população, e em quais estados e regiões do Brasil elas se encontram. Levando em consideração esse contexto, e ainda, que os Jogos Paralímpicos RIO 2016 seriam realizados no Brasil, o presente estudo teve como objetivo mapear geograficamente por estados e regiões do Brasil a distribuição dos atletas paralímpicos que competiram nas modalidades de natação e atletismo bem como conhecer suas deficiências, durante 0 ano de 2015, nas três fases do Circuito Loterias Caixa, sendo essa considerada a maior competição de alto rendimento no Brasil e preparatória para os Jogos Paralímpicos RIO 2016.

\section{MÉTODO}

O projeto foi aprovado pelo Comitê de Ética e Pesquisa da Universidade Federal de Minas Gerais (CAAE 44007915.0.0000.5149) e recebeu autorização da Academia Paralímpica Brasileira (APB) e do Comitê Paralímpico Brasileiro (CPB).

\subsection{AMOSTRA}

Os dados dos atletas paralímpicos do presente estudo foram coletados durante as três fases nacionais do Circuito Loterias Caixa, na cidade de São Paulo, nos meses de julho, setembro e novembro de 2015, ano que antecedeu os jogos paralímpicos do Rio 2016. 0 Circuito Loterias Caixa é organizado pelo Comitê Paralímpico Brasileiro e patrocinado pelas Loterias Caixa. Este é o mais importante evento paralímpico nacional de atletismo, natação e halterofilismo. Tem como objetivo desenvolver as práticas desportivas em todos os municípios e estados brasileiros, além de melhorar o nível técnico das modalidades e dar oportunidades competitivas para atletas de elite e aos novos talentos do esporte paralímpico do país. Também é um evento teste e de preparação para os Jogos Paralímpicos do Rio 2016. Os atletas que participam dos Circuito Loterias Caixa devem ter atingido um índice mínimo estabelecido pela competição, sendo assim, esses atletas já participaram previamente de competições municipais e regionais para atingirem esse índice e posteriormente competirem em nível nacional.

No banco de dados inicial havia um total de 2.354 atletas, distribuídos nas três fases competitivas. Contudo, com o objetivo de caracterizar e distribuir geograficamente por estados e regiões os atletas paralímpicos brasileiros, foram excluídos da análise os atletas que estavam com nomes duplicados e/ou na mesma prova. Assim, as análises realizadas são em relação ao total de 1.708 atletas paralímpicos brasileiros das modalidades natação e atletismo que competiram nas três fases do Circuito Loterias Caixa. Em relação aos atletas da natação, 0 banco de dados inicial havia um total de 1.331 atletas, distribuídos nas três fases competitivas; foram excluídos da análise os atletas que estavam com nomes duplicados $(n=418)$, ou seja, que participaram em mais de uma prova ou fase do Circuito. Já em relação aos atletas do atletismo inicialmente tinha-se um total de 1.023 atletas, foram excluídos da análise 228. 


\subsection{PROCEDIMENTOS}

Para realizar o presente estudo os pesquisadores, após obterem a aprovação do Comitê de Ética em Pesquisa, solicitaram a anuência para a APB do CPB para a realização da pesquisa. Após essa autorização, os pesquisadores enviaram para a diretoria técnica do CPB uma planilha modelo em Excel com os dados necessários para a realização dessa pesquisa. Os pesquisadores não participaram presencialmente das três fases nacionais. No entanto, após a finalização das três fases do Circuito Loterias Caixa, os pesquisadores realizaram cinco visitas à Sede do CPB em Brasília/DF, com o intuito de organizar juntamente com a área técnica o banco de dados para a presente pesquisa que teve como fonte principal os registros realizados pelo CPB durante cada fase do Circuito. Com isso, as informações necessárias foram compiladas em conjunto com o CPB numa planilha de Excel, sendo que para a montagem desse banco de dados foram necessárias a seguintes informações: dados das provas, a deficiência de cada atleta, o estado e região de atleta. Após termos uma planilha totalmente completa e estruturada a análise dos dados foi realizada.

\subsection{ANÁLISE ESTATÍSTICA}

A tabulação e organização do banco de dados foi realizada em planilha do Microsoft Excel versão 13.0. A análise dos dados foi realizada utilizando-se as ferramentas estatísticas do software IBM SPSS Statistics - versão 20, sendo composta por estatística descritiva. Os dados são apresentados em números absolutos e valores percentuais (\%), levando-se em consideração a frequência absoluta (análise geral) e relativa (sexo, estado, região, modalidade).

\section{RESULTADOS}

A Tabela 1 demonstra a distribuição dos atletas nas modalidades de atletismo e natação de acordo com o sexo e as deficiências. No total, participaram 913 atletas da natação e 795 atletas do atletismo paralímpico brasileiro.

Tabela 1 - Distribuição dos atletas nas modalidades de atletismo e natação de acordo com o sexo e as deficiências.

\begin{tabular}{ccccccc}
\hline Sexo & $\mathbf{N}$ & $\%$ & Natação (N) & Natação (\%) & Atletismo (N) & Atletismo (\%) \\
\hline Feminino & 632 & 37 & 374 & 41 & 258 & 32,5 \\
Masculino & 1076 & 63 & 539 & 59 & 537 & 67,5 \\
Deficiência & $\mathrm{N}$ & $\%$ & Natação (N) & Natação (\%) & Atletismo (N) & Atletismo (\%) \\
Físico-motora & 1118 & 65,3 & 633 & 69,3 & 485 & 60,8 \\
Intelectual & 161 & 9,4 & 94 & 10,3 & 67 & 8,4 \\
Visual & 429 & 25,1 & 186 & 20,4 & 243 & 30,6 \\
Total & 1708 & 100 & 913 & 100 & 795 & 100 \\
\hline
\end{tabular}

Fonte: dados da pesquisa

A Figura 1 demonstra a distribuição geográfica dos atletas por estados e regiões do Brasil. Podemos observar que a maioria dos atletas se encontra na Região Sudeste. Já a 
distribuição dos atletas de acordo com as deficiências por estados e regiões do Brasil está representada na Figura 2. A deficiência físico-motora foi a mais prevalente entre os atletas, tanto no atletismo quanto na natação.

Figura 1 - Distribuição geográfica dos atletas das modalidades de atletismo e natação por estados e regiões do Brasil. F=Feminino; M=Masculino.

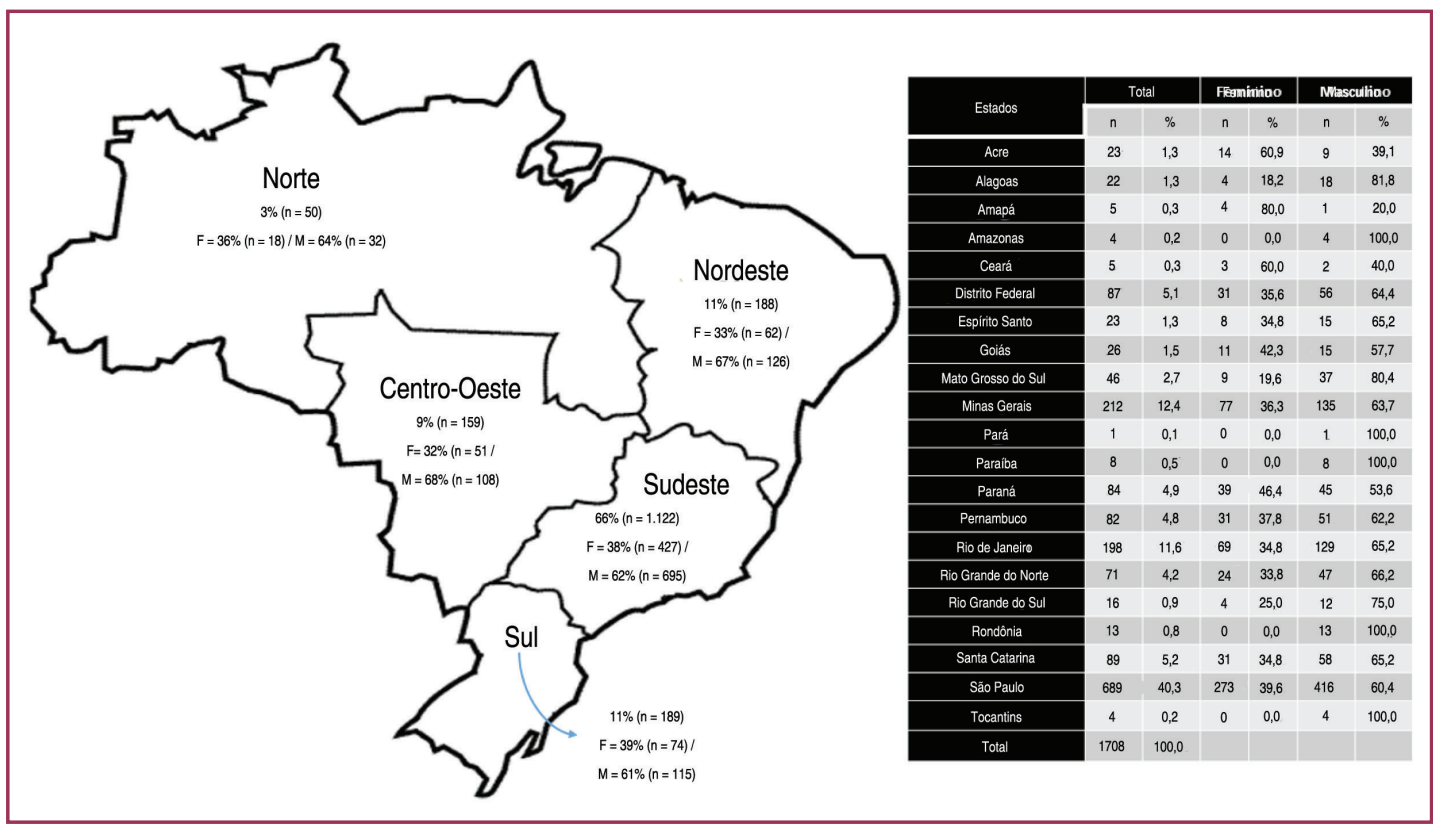

Fonte: dados da pesquisa

Figura 2- Distribuição dos atletas de atletismo e natação de acordo com as deficiências por estados e regiões do Brasil. F=Físico-Motora; I=intelectual; N=Nanismo; V=Visual.

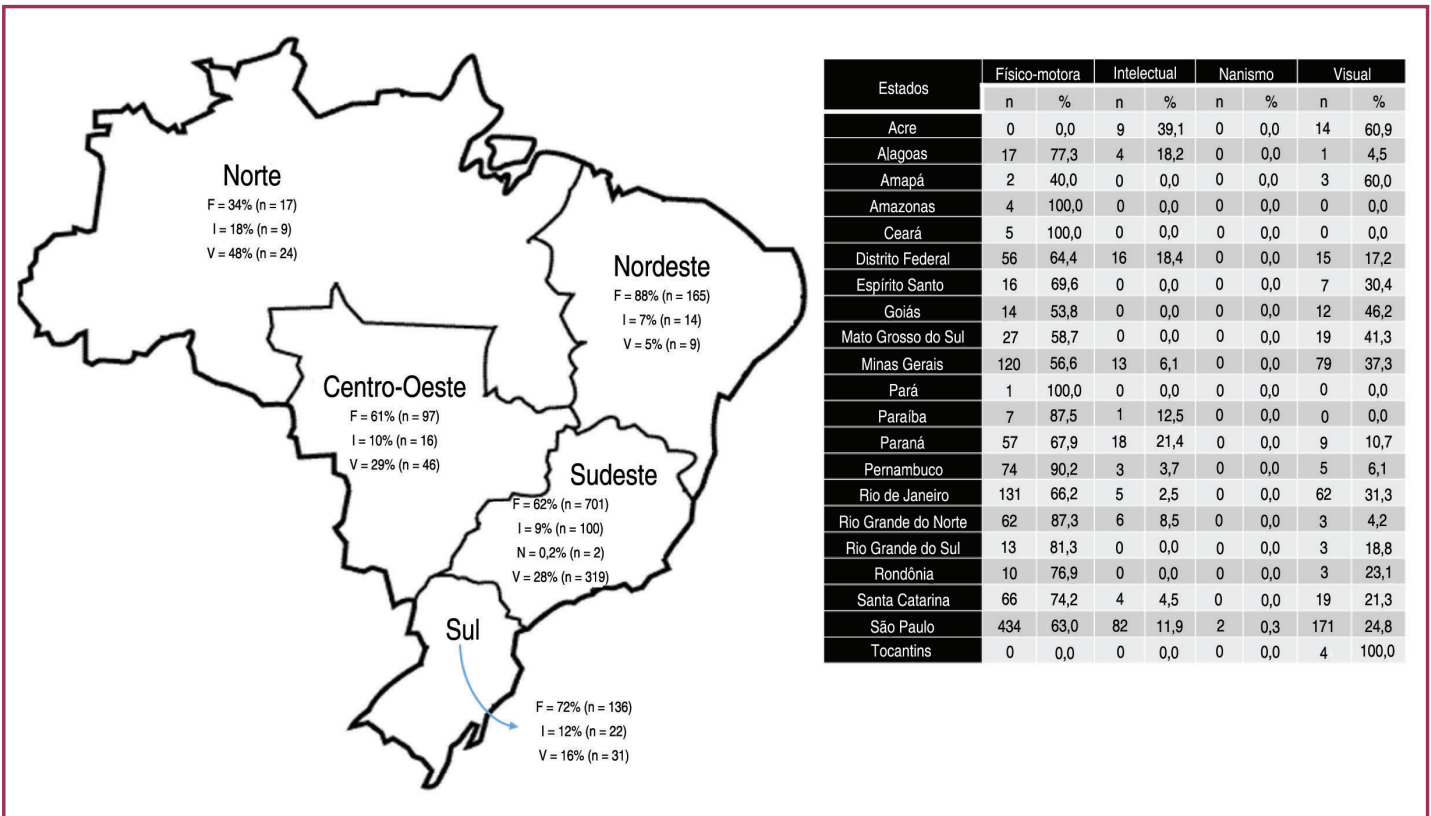

Fonte: dados da pesquisa

Na Figura 3 apresentamos a distribuição dos atletas da natação por estados e regiões do Brasil, e a distribuição de acordo com a deficiência na Figura 4. Observamos que a Região Sudeste apresenta maior número de atletas da natação e a deficiência físico-motora foi prevalente. 
Figura 3 - Distribuição dos atletas da natação por estados e regiões do Brasil. F=Feminino; M=Masculino.

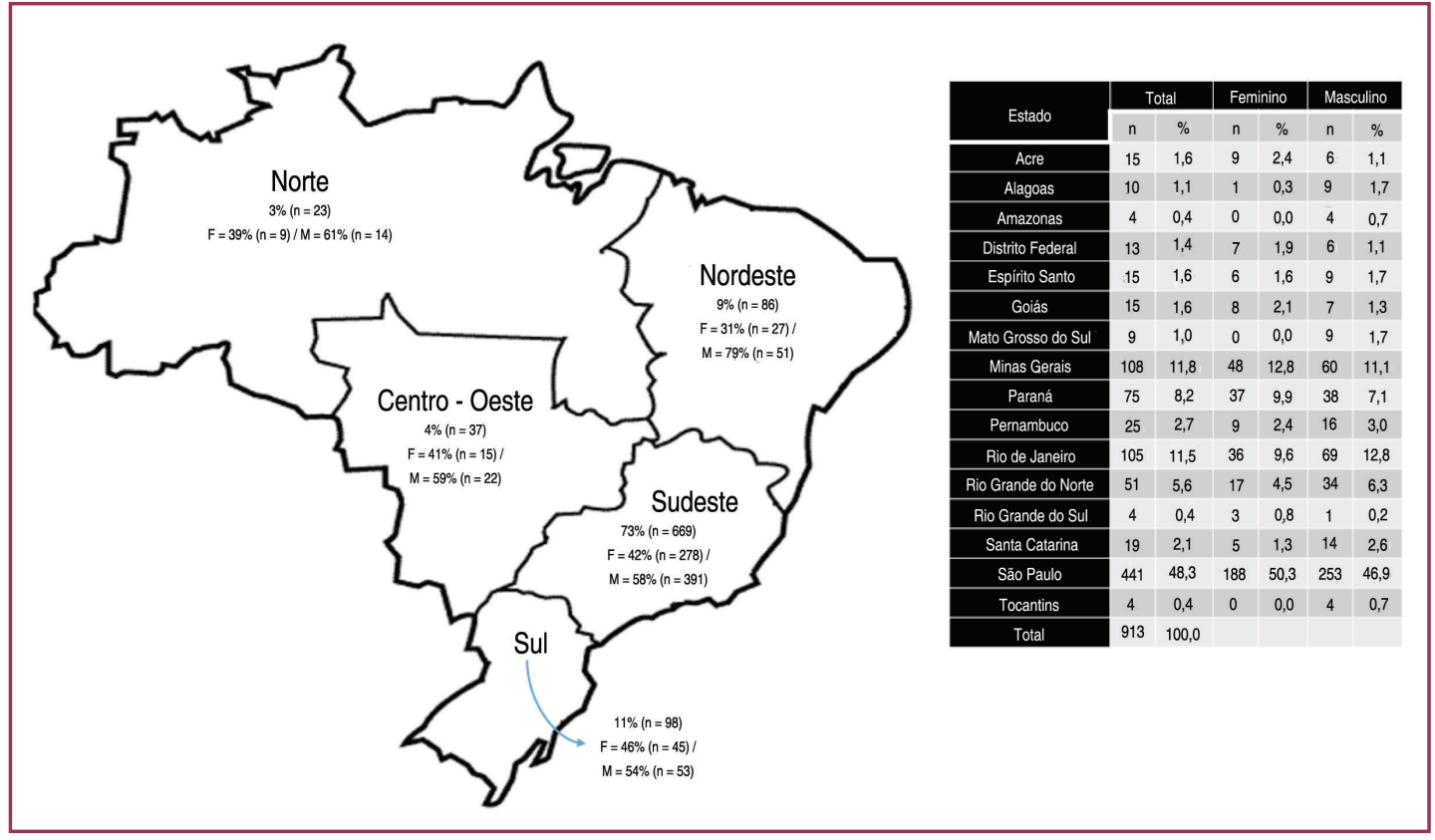

Fonte: dados da pesquisa

Figura 4 - Distribuição dos atletas da natação de acordo com a deficiência por estados e regiões do Brasil. F=Físico-Motora; I=intelectual; V=Visual.

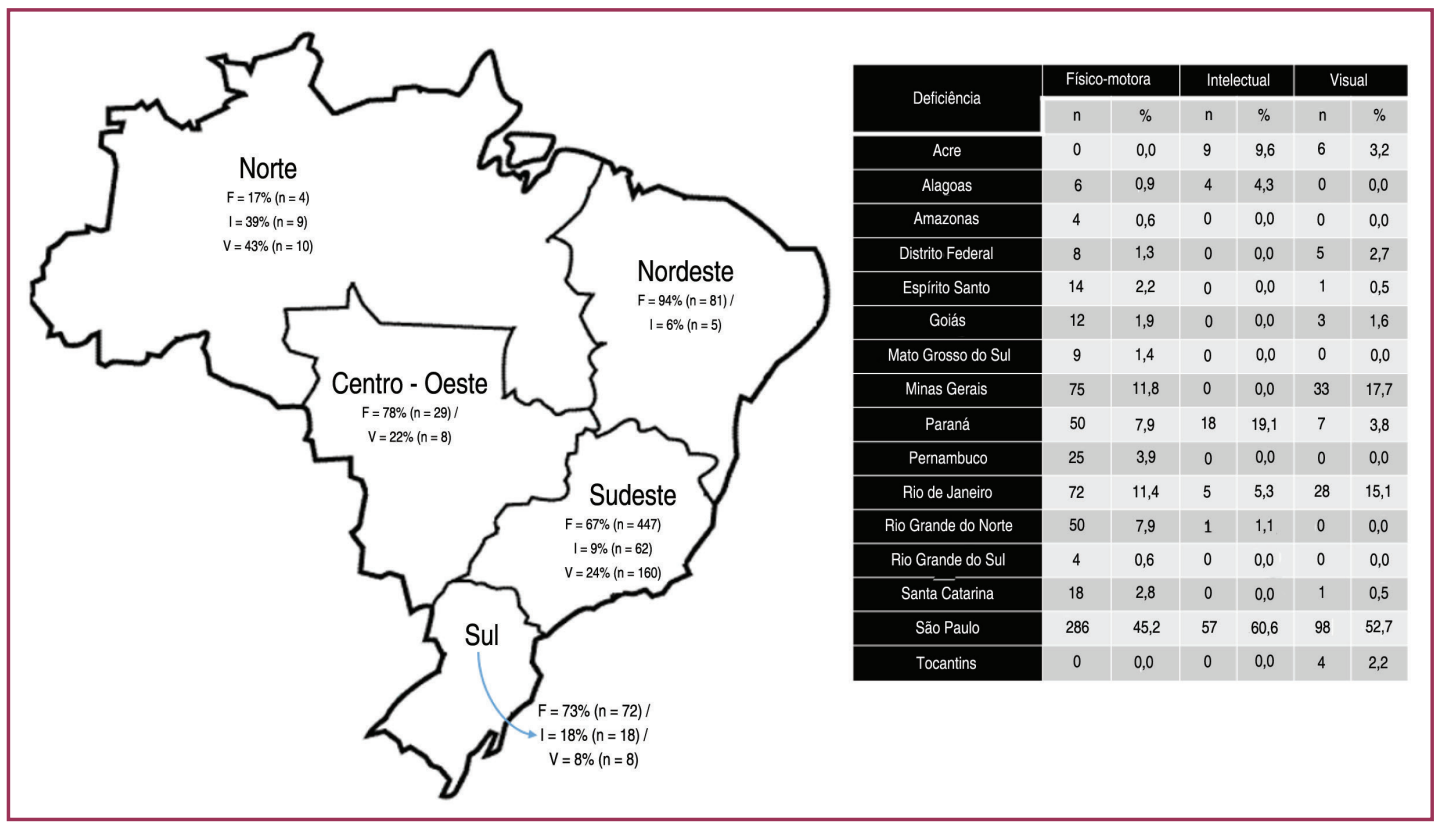

Fonte: dados da pesquisa

Na Figura 5 apresentamos a distribuição dos atletas do atletismo de acordo com o sexo por estados e regiões do Brasil e na Figura 6 estão representados os atletas de acordo com as deficiências por estados e regiões do Brasil. Foi possível observar que o sexo masculino e a deficiência físico-motora foram prevalentes entre os atletas do atletismo. 
Figura 5 - Distribuição dos atletas do atletismo de acordo com o sexo por estados e regiões do Brasil. F=Feminino; M=Masculino.

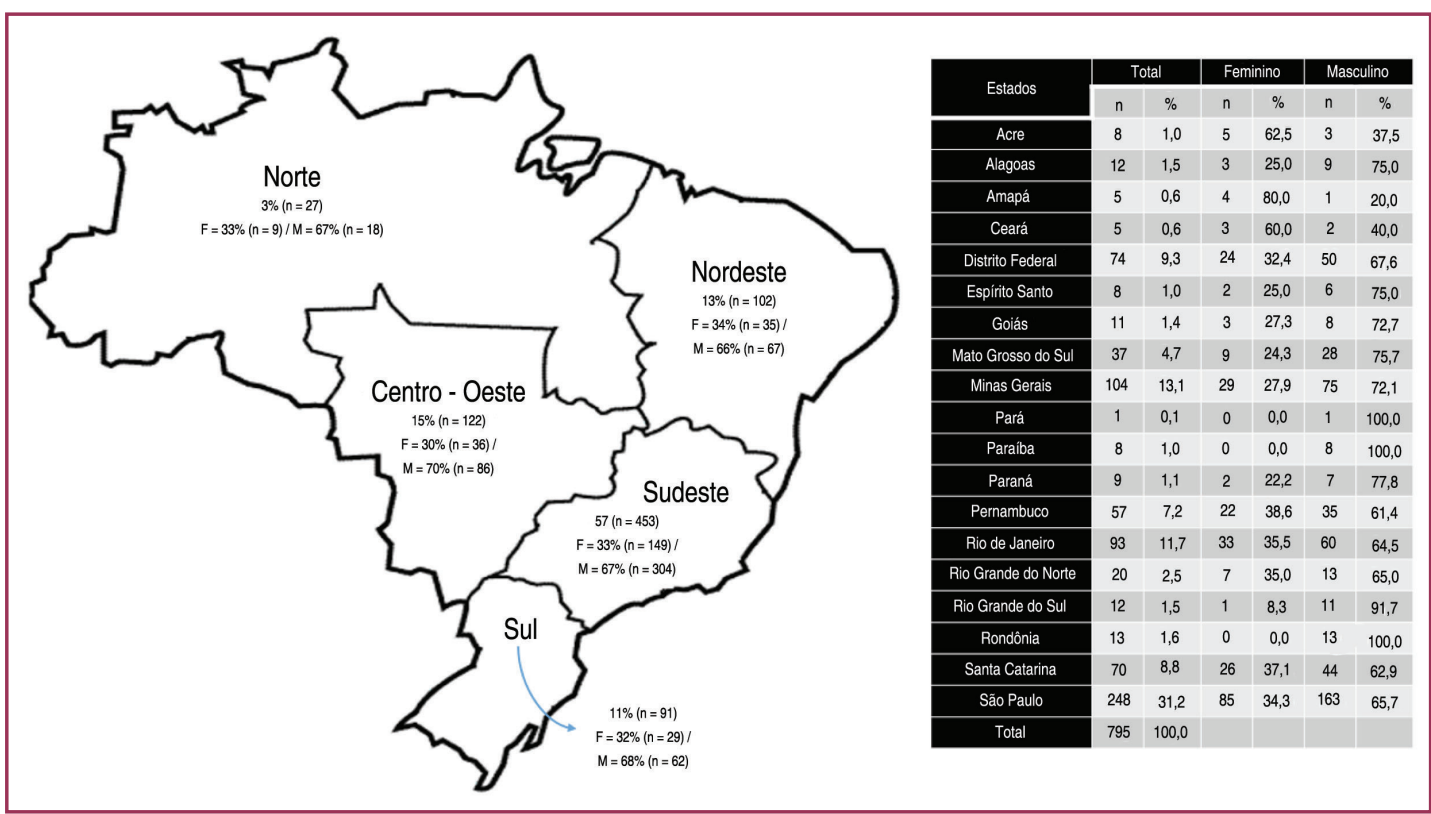

Fonte: dados da pesquisa

Figura 6 - Distribuição dos atletas do atletismo de acordo com as deficiências por estados e regiões do Brasil. F=Físico-Motora; N=Nanismo; I=intelectual; V=visual

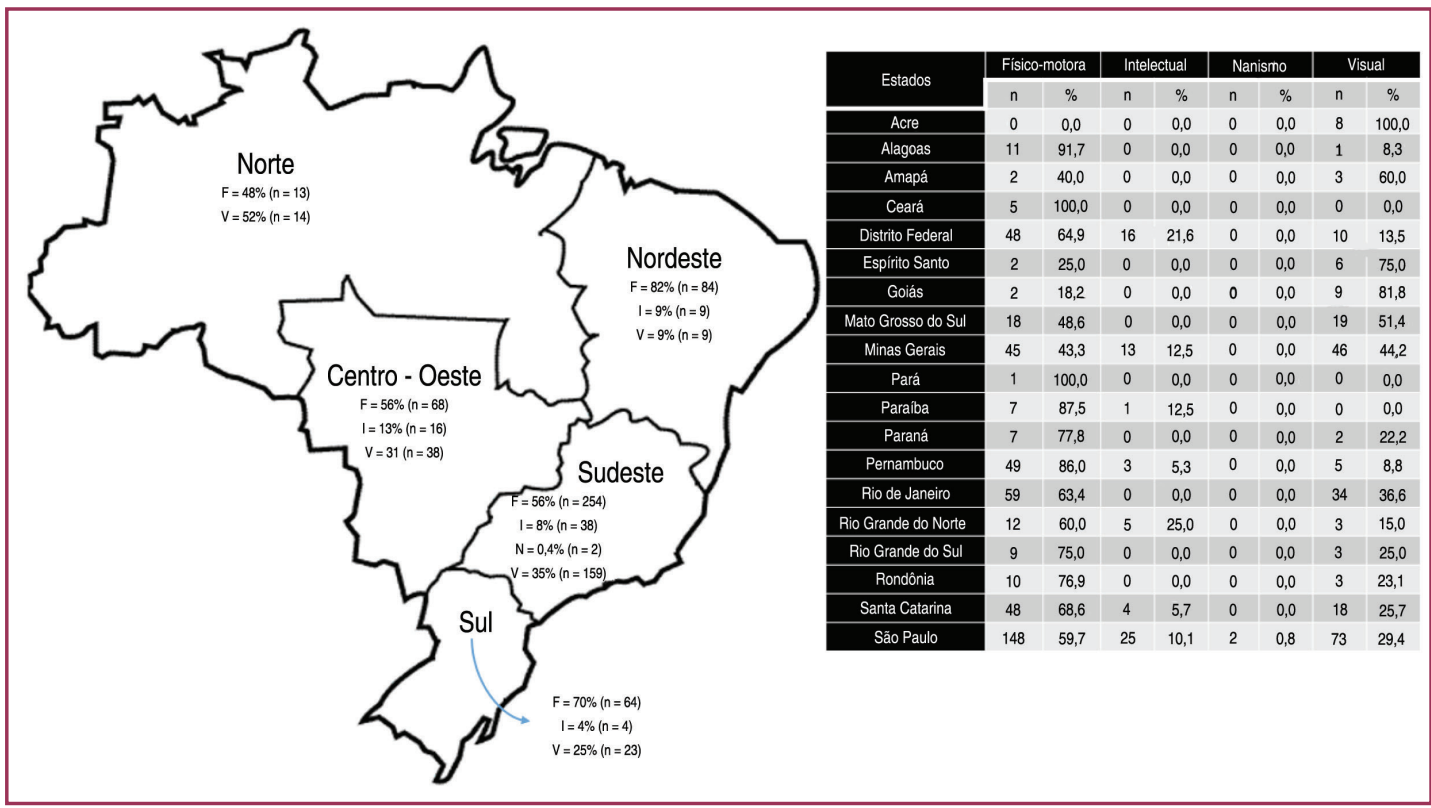

Fonte: dados da pesquisa

\section{DISCUSSÃO}

O presente estudo mapeou geograficamente, por estados e regiões do Brasil, a distribuição dos atletas paralímpicos brasileiros, bem como suas respectivas deficiências nas modalidades paralímpicas de natação e atletismo. Pode-se observar nos resultados do presente estudo que o maior número de atletas se concentra na Região Sudeste e, de acordo com a deficiência, houve a prevalência de atletas com deficiência físico-motora $(65,3 \%)$. 
A Região Sudeste do Brasil é composta por cidades que historicamente são responsáveis pela implementação do esporte paralímpico no Brasil (ARAÚJO, 2011), o que pode explicar esse número elevado de atletas paralímpicos encontrados no presente estudo. Em contrapartida, a Região Nordeste do país possui o menor número de atletas paralímpicos, demonstrado, dessa maneira, a necessidade de estratégias nessa região para melhorar 0 desenvolvimento do esporte paralímpico.

Levando em consideração os achados das deficiências, é importante salientar que para competir nas modalidades paralímpicas de atletismo e natação, os atletas devem ter deficiência física, visual ou intelectual, e precisam ser elegíveis no sistema de classificação esportiva paralímpica, sistema esse que visa distribuir os atletas em classes esportivas para competirem de maneira igualitária e justa (COSTA; SOUZA, 2004; GONZALEZ; SILVA, 2007; MARQUES et al., 2012; MARQUES et al., 2009; TWEEDY; VANLANDEWIJK, 2011).

Diante disso, a deficiência com maior prevalência durante o Circuito Loterias Caixa no ano de 2015 foi a DF, com 65,5\% dos atletas. Essa predominância pode ser atribuída ao maior número de classes esportivas e provas competitivas existentes para esse tipo de deficiência (IPC, 2016a, 2016b). Por outro lado, a Região Nordeste é a região que mais possui pessoas com DF no Brasil (1,6\%) (MALTA et al., 2016), o que contradiz o número de atletas paralímpicos encontrado nessa região no nosso estudo.

Contudo, a deficiência que mais atinge os brasileiros é a DV (3,6\% da população) e a Região Sul do país é a que mais possui pessoas com DV (5,9\%; $n=1698)$ (MALTA et al., 2016). O que pode em parte explicar os achados do nosso estudo, no qual encontramos que a DV representa $24 \%$ dos atletas paralímpicos, sendo que a maioria reside na Região Sudeste. Entretanto, mesmo que a Região Sul do Brasil seja a que mais possui pessoas com DV (MALTA et al., 2016), observamos no presente estudo que a Região Sul do país possui um número pequeno de atletas paralímpicos com DV que participaram do Circuito Loterias Caixa. Recentemente, um estudo realizado por Mazo e colaboradores (2018) relatou que o Rio Grande do Sul foi um dos estados com menor número de atletas previstos para fazerem parte da Delegação Paralímpica Brasileira, e que, apesar do esporte para pessoas com deficiência estar presente na Região Sul do país há mais de 45 anos (BEGOSSI; MAZO, 2016; CARMONA, 2015), o desenvolvimento do esporte de alto rendimento parece estar aquém nessa região.

Em geral, a baixa participação de pessoas com DV em atividade física adaptada pode ser compreendida de acordo com o contexto em que estão inseridas, como, por exemplo, as dificuldades pessoais e ambientais (RIMMER et al., 2004). As dificuldades ambientais podem estar associadas aos componentes de acessibilidade (obstáculos, buracos, falta de adaptação), segurança (quedas e colisões), transporte (estrutura, orientação e comunicação) e a falta de programas de atividade física adaptada para essa deficiência (LEGOOD; SCUFFHAM; CRYER, 2002; ANDRADE; ELY, 2012; MARMELEIRA et al., 2014). Os estudos de Esteves et al. (2015) e Cruz et al. (2017) demonstraram que atletas paralímpicos apresentaram menor escore no domínio "meio ambiente" comparado aos domínios físico, psicológico e relações sociais referente ao questionário de qualidade de vida (WHOQOL-bref), confirmando a hipótese de baixa participação por dificuldades ambientais. Além disso, os diversos fatores pessoais, como a percepção de autoeficácia física e social, a insegurança em sair de casa, a desmotivação, as condições de saúde, a própria idade e a falta de recursos financeiros, podem influenciar 
na prática da atividade física (VAN DER PLOEG et al., 2004; MARMELEIRA et al., 2014). No entanto, não avaliamos no presente estudo a interferência desses fatores na vida dos atletas.

Na modalidade de atletismo paralímpico, há grande participação dos atletas de ambos os sexos, que apresentam DF, DV e DI. As provas da modalidade de atletismo dividem-se em corridas, saltos, arremessos e lançamentos (COSTA; SOUSA, 2004). Nesse contexto, no presente estudo a modalidade de atletismo teve 795 atletas paralímpicos participando no ano de 2015 do Circuito Loterias Caixa, com prevalência maior de atletas da Região Sudeste (453 atletas), sendo 60,8\% ( $n=485)$ atletas com DF, 30,6\% $(n=243)$ atletas com DV e 8,4\% $(n=67)$ atletas com DI. Por outro lado, o estudo de Medeiros (2014) relatou que no Circuito Loterias Caixa de 2011, 61 atletas da modalidade de atletismo tinham DF. Dessa forma, podese observar a evolução no número de participantes de DF de 2011 para 2015. Na modalidade natação, encontramos um resultado similar ao que foi demonstrado na modalidade de atletismo, com uma maior prevalência de atletas de natação também na Região Sudeste (669 atletas) do Brasil, sendo, $67 \%$ atletas com DF, $24 \%$ de atletas com DV e $9 \%$ atletas com DI.

Por outro lado, o esporte paralímpico, por ser considerado de alto rendimento, exige investimentos financeiros municipais, estaduais e federal, bem como incentivos sociocultural e esportivo em todas os municípios, estados e regiões do Brasil. No presente estudo pode-se observar pela distribuição geográfica, tanto por estado quanto por regiões, que 0 desenvolvimento para o esporte paralímpico não está sendo executado de maneira igualitária. De acordo com Furtado (2017), no Brasil não são todas as regiões que têm estrutura adequada e incentivos socioeconômicos capazes de desenvolver projetos e programas para pessoas com deficiência com objetivo de prepará-los para o esporte de alto rendimento. Apesar dessa realidade, existem entidades não governamentais e sem fins lucrativos que investem no esporte paralímpico. E ainda, podemos destacar o trabalho e os esforços do CPB na expansão do conhecimento, formando recursos humanos em todos os estados e regiões do Brasil, para que assim o desenvolvimento local possa ser otimizado em prol do esporte paralímpico. 0 CPB possui uma série de ações no Brasil, como, por exemplo a realização do Congresso Internacional Paralímpico, que ocorre a cada dois anos em algum estado do Brasil, bem como os cursos de formação de nível técnico e de capacitação, a realização do Festival Paralímpico que ocorre anualmente no mês de setembro em todas os estados do Brasil e no Distrito Federal com o intuito de divulgar o esporte paralímpico, tanto para pessoas com deficiência quanto para pessoas sem deficiência, e ainda a realização de eventos competitivos a nível regional e nacional, como o Circuito Loterias Caixa. Foi a partir dessas ações do CPB em parceria com alguns municípios, estados e governo federal que foi possível realizar o desenvolvimento do esporte paralímpico brasileiro nos últimos anos, que levaram o Brasil a se firmar no cenário mundial, no qual, desde a Paralimpíada de Pequim em 2008, o Brasil permanece entre os dez melhores colocados em Paralimpíadas (IPC, 2014; CARDOSO, 2018). Ao longo de todos esses anos as modalidades de atletismo e natação foram a que mais conquistaram medalhas até o momento para o Brasil (GONZALEZ; SILVA, 2007).

De acordo com Furtado (2017), houve aumento do investimento financeiro para as modalidades esportivas paralímpicas nos últimos anos, por meio de um convênio realizado entre o CPB e o governo federal (Ministério dos Esportes) nos últimos anos, com intuito de preparar as seleções paralímpicas para os Ciclos Paralímpicos de Londres 2012 e RIO 2016. O Atletismo $(R \$ 1.345 .882,08)$ e a Natação $(R \$ 1.422 .391,76)$ foram as modalidades que 
mais receberam investimentos (FURTADO, 2017). Houlihan e Zeng (2013) afirmaram em seu estudo que os países que aplicaram seus recursos em modalidades esportivas paralímpicas têm maiores chances de obter sucesso, sendo utilizado como estratégia para maximizar o retorno do investimento realizado no alto rendimento, demonstrado por meio de conquistas de medalhas em Jogos Paralímpicos.

Por sua vez, é importante ressaltar que não é somente a conquista de uma medalha paralímpica que envolve o esporte paralímpico, mas, sim, a mudança de paradigmas em relação às pessoas com deficiência, e por isso deve-se incentivar a prática esportiva adaptada para pessoas com DF, DV e DI em qualquer nível esportivo, seja como meio de reabilitação física ou psíquico-social, recreativa ou no paradesporto. Independentemente do nível competitivo, a prática esportiva possibilita à pessoa com deficiência se sentir e se ver de maneira mais positiva, favorecendo a integração social e melhorando a sua qualidade de vida (LABRONICI et al., 2000), além, da melhora significativa do estado de humor, depressão e ansiedade (CAMPBELL; JONES, 1994).

Embora, no presente estudo, possa-se observar, uma distribuição heterogênica de atletas paralímpicos nas regiões do Brasil, o nosso país vem sendo considerado no meio do esporte paralímpico como uma potência paralímpica, devido aos resultados alcançados nos últimos anos em competições internacionais. Essas mudanças refletem 0 amadurecimento no desenvolvimento social, econômico e político voltado à pessoa com deficiência no país. São mudanças influenciadas por ações governamentais e não governamentais envolvendo parcerias entre o CPB, municípios, estados e governo federal (Ministério dos Esportes), que visam melhorar por meio de políticas públicas o acesso de crianças e de jovens com algum tipo de deficiência à prática esportiva. Em contrapartida, podemos perceber o desenvolvimento do esporte paralímpico por meio das Paralimpíadas Escolares, Clínicas de Desporto Paralímpico, Programa Segundo Tempo para Pessoas com Deficiência, Bolsa Atleta, Circuito Loterias Caixa, entre outros (FURTADO, 2017).

\section{CONCLUSÃO}

Podemos concluir que a região brasileira com o maior número de atletas paralímpicos que participaram do Circuito Loterias Caixa no ano de 2015 nas modalidades de atletismo e natação foi a Sudeste, e a região com menor número de atletas nas fases competitivas foi a Região Norte. Encontramos uma predominância da deficiência físico-motora nesses atletas, tanto no atletismo quanto na natação. Essas informações são importantes para 0 desenvolvimento do esporte paralímpico no Brasil, pois é a partir desses atletas que surgem os medalhistas paralímpicos brasileiros, e ainda, essas competições de 2015 serviram como evento preparatório para os Jogos Paralímpicos do Rio 2016, nos quais o Brasil finalizou a competição no $8^{\circ}$ lugar na classificação geral, sendo que as modalidades que mais conquistaram medalhas foram 0 atletismo (33 medalhas) e a natação (19 medalhas), destacando mais uma vez a importância do Circuito Loterias Caixa para os atletas paralímpicos brasileiros. 


\section{REFERÊNCIAS}

ANDRADE, Isabela Fernandes, ELY, Vera Helena Moro Bins. Edificações históricas preservadas: intervir para torná-las acessíveis. Revista Ação Ergonômica, v. 7, n. 2, 2012. Disponível em: http://www.abergo.org.br/revista/index.php/ae/article/view/185. Acesso em: 02 maio 2019.

ARAÚJO, Paulo Ferreira. Desporto adaptado no Brasil. São Paulo: Phorte, 2011. Disponível em: http://repositorio.unicamp.br/bitstream/REPOSIP/275284/1/Araujo_PauloFerreirade_D.pdf. Acesso em: 02 maio 2019.

BAILEY, Steve. Athlete first: A history of the Paralympic movement. West Sussex: John Wiley \& Sons, 2008.

BEGOSSI, Tuany Defaveri; MAZO, Janice Zarpellon. O percurso esportivo das mulheres pioneiras no cenário paralímpico sul-rio-grandense. Revista Brasileira Ciência e Movimento, v. 24, n. 4, p. 143-155, 2016. Disponível em: https://portalrevistas.ucb.br/index.php/RBCM/article/ view/6815. Acesso em: 02 maio 2019.

CAMPBELL, Elizabeth; JONES, Graham. Psychological well-being in wheelchair sport participants and nonparticipants. Adapted Physical Activity Quarterly, v. 11, n. 4, p. 404-415, 1994. Disponível em: https://www.researchgate.net/publication/232596534 Psychological WellBeing in Wheelchair Sport Participants and Nonparticipants. Acesso em: 02 maio 2019.

CARDOSO, Vinícius Denardin et al. A tecnologia no esporte paralímpico. Pensar a Prática, v. 21, n. 3, 2018. Disponível em: https://www.researchgate.net/publication/3282224816 A TECNOLOGIA NO ESPORTE PARALIMPICO. Acesso em: 05 julho 2019.

CARMONA, Eduardo Klein. Atletas deficientes visuais sul-rio-grandenses nos Jogos Paralímpicos: cenários e memórias. 2015. 110 f. Dissertação (Mestrado em Ciências do Movimento Humano) - Escola de Educação Física, Fisioterapia e Dança, Universidade Federal do Rio Grande do Sul, Porto Alegre, 2015.

COSTA, Alberto Martins; SOUSA, Sônia Bertoni. Educação física e esporte adaptado: história, avanços e retrocessos em relação aos princípios da integração/inclusão e perspectivas para o século XXI. Revista Brasileira de Ciências do Esporte, v. 25, n. 3, 2004. Disponível em: http:// revista.cbce.org.br/index.php/RBCE/article/view/236. Acesso em: 02 maio 2019.

CRUZ, Analice Rodrigues; RODRIGUES, Dayane Ferreira; MELLO, Marco Túlio; SIMIM, Mário Antônio de Moura; ROSA, João Paulo Pereira; WINCKLER, Ciro; SILVA, Andressa. Perception of sleep and quality of life in paralympic athletes: comparison between athletes with physical and visual disabilities. Journal of Physical Education, v. 28, 2017. Disponível em: http://www.scielo. br/scielo.php?script=sci_arttext\&pid=S2448-24552017000100135. Acesso em: 02 maio 2019.

DUARTE, Edison; SILVA, Magno Passos. Pessoas com Deficiência: Aspectos Epidemiológicos. In: MELLO, Marco Tulio; WINCKLER, Ciro. Esporte Paralímpico. São Paulo: Atheneu, 2012. p.3-14.

ESTEVES, Andrea Maculano et al. Avaliação da qualidade de vida e do sono de atletas paralímpicos brasileiros. Revista Brasileira de Medicina do Esporte, v. 21, n. 1, p. 53-56, 2015. Disponível em: http://www.scielo.br/scielo.php?pid=S1517-86922015000100053\&script=sci abstract\&tlng=pt. Acesso em: 02 maio 2019. 
FURTADO, Sabrina. As ações, os projetos e o financiamento do Comitê Paraolímpico Brasileiro no período de 2010 a 2015. 130 f. Dissertação (Mestrado em Educação Física) - Universidade Federal do Paraná, Curitiba, 2017. Disponível em: https://acervodigital.ufpr.br/ handle/1884/47463? show=full. Acesso em: 02 maio 2019.

GONZALEZ, Jane Silva; SILVA, Rodrigo Pereira. Os Jogos Paraolímpicos: o contexto histórico e atual. Olympic studies, p.801-814, 2007.

HOULIHAN, Barrie; ZHENG, Jinming. The Olympics and elite sport policy: Where will it all end? The international journal of the history of sport, v. 30, n. 4, p. 338-355, 2013. Disponível em: https://researchportal.northumbria.ac.uk/en/publications/the-olympics-and-elitesport-policy-where-will-it-all-end(5e5c6b1b-b781-4f1d-9af5-8bbfe5559ae5)/export.html. Acesso em: 02 maio 2019.

INTERNATIONAL PARALYMPIC COMMITTEE ATHLETICS CLASSIFICATION RULES AND REGULATION. Official website of World Para Athletics. Jan. 2014. Disponível em: http://www. paralympic.org/athletics. Acesso em: 04 de abr. 2018.

INTERNATIONAL PARALYMPIC COMMITTEE (IPC). Swimming classification. 2016a. Disponível em: http://www.paralympic.org/swimming/classification. Acesso em: 04 jul. 2019.

INTERNATIONAL PARALYMPIC COMMITTEE(IPC). Swimming classification. 2016b. Disponível em: http://www.paralympic.org/athletics/classification. Acesso em: 04 jul. 2019.

LABRONICl, Rita Helena Duarte Dias et al. Esporte como fator de integração do deficiente físico na sociedade. Arquivos de Neuro-Psiquiatria, 2000. Disponível em: http://www.scielo. br/scielo.php?pid=S0004-282X2000000600017\&script=sci abstract\&tlng=pt. Acesso em: 02 maio 2019.

LEGOOD, Rosa; SCUFFHAM, Paul; CRYER, Caroline. Are we blind to injuries in the visually impaired? A review of the literature. Injury prevention, v. 8, n. 2, p. 155-160, 2002. Disponível em: https://injuryprevention.bmj.com/content/8/2/155.short. Acesso em: 02 maio 2019.

MALTA, Deborah Carvalho et al. Prevalência autorreferida de deficiência no Brasil, segundo a Pesquisa Nacional de Saúde, 2013. Ciência \& Saúde Coletiva, v. 21, p. 3253-3264, 2016. Disponível em: http://www.scielo.br/scielo.php?pid=S1413-81232016001003253\&script=sci abstract\&tlng=pt. Acesso em: 02 maio 2019.

MARMELEIRA, José et al. Physical activity patterns in adults who are blind as assessed by accelerometry. Adapted Physical Activity Quarterly, v. 31, n. 3, p. 283-296, 2014. Disponível em: https://www.ncbi.nlm.nih.gov/pubmed/25028478. Acesso em: 02 maio 2019.

MARQUES, Renato Francisco Rodrigues et al. investigação sobre as configurações sociais do subcampo do esporte paralímpico no Brasil: os processos de classificação de atletas. Revista da Educação Física/UEM, v. 23, n. 4, p. 515-527, 2012. Disponível em: http://www.scielo.br/ scielo.php?pid=S1983-30832012000400002\&script=sci abstract\&tlng=pt. Acesso em: 02 maio 2019.

MARQUES, Renato Francisco Rodrigues et al. Esporte olímpico e paraolímpico: coincidências, divergências e especificidades numa perspectiva contemporânea. Revista Brasileira de Educação Física e Esporte, v. 23, n. 4, p. 365-377, 2009. Disponível em: http:// www.scielo.br/scielo.php?pid=s1807-55092009000400006\&script=sci_abstract\&tlng=pt. Acesso em: 02 maio 2019. 
MAZO, Janice Zarpellon et al. Rio 2016 Paralympic games: sports memories of athletes of Rio Grande do Sul. Brazilian Journal of Education, Technology and Society, v. 11, n. 1, p. 87-104, 2018. Disponível em: https://www.academia.edu/37963618/RIO 2016 PARALYMPIC GAMES SPORTS MEMORIES OF ATHLETES OF RIO GRANDE DO SUL. Acesso em: 02 maio 2019.

MEDEIROS, Robson da Silva. Impacto do atletismo paralímpico na qualidade de vida de pessoas com deficiência física. 2014. 59 f. Dissertação (Mestrado em Ciências da Saúde) Universidade Federal de Uberlândia, Uberlândia, 2014. Disponível em: https://repositorio.ufu.br/ handle/123456789/12834. Acesso em: 02 maio 2019.

PARSONS, Andrew; WINCKLER, Ciro. Esporte e a pessoa com deficiência: contexto histórico. MELLO, Marco Tulio; WINCKLER, Ciro, (org.). Esporte Paralímpico. Rio de Janeiro: Atheneu, 2012.

RIMMER, James H. et al. Physical activity participation among persons with disabilities: barriers and facilitators. American journal of preventive medicine, v. 26, n. 5, p. 419-425, 2004. Disponível em: https://www.sciencedirect.com/science/article/pii/S0749379704000297. Acesso em: 02 maio 2019.

STEADWARD, Robert; PETERSON, Cynthia. Paralympics. Edmonton: One Shot Holdings, 1997.

TWEEDY, Sean M.; VANLANDEWIJCK, Yves C. international Paralympic Committee position stand-background and scientific principles of classification in Paralympic sport. British Journal of Sports Medicine, v. 45, n. 4, p. 259-269, 2011. Disponível em: https://bjsm.bmj.com/ content/45/4/259.long. Acesso em: 02 maio 2019.

VAN DER PLOEG, Hidde P. et al. Physical activity for people with a disability. Sports medicine, v. 34, n. 10, p. 639-649, 2004. Disponível em: https://link.springer.com/ article/10.2165/00007256-200434100-00002. Acesso em: 02 maio 2019.

\section{Agradecimentos:}

Os autores agradecem a Universidade Federal de Minas Gerais, o Centro de Estudos em Psicobiologia e Exercício (CEPE), o Centro Multidisciplinar em Sonolência e Acidentes (CEMSA), a Fundação de Amparo à Pesquisa do Estado de Minas Gerais (FAPEMIG), a Coordenação de Aperfeiçoamento de Pessoal de Nível Superior (CAPES), o Conselho Nacional de Desenvolvimento Científico e Tencológico (CNPQ) e a Academia Paralímpica Brasileira do Comitê Paralímpico Brasileiro. Agradecemos ao Mario Antônio Simim pelo apoio na análise dos dados. 